\title{
Cidade na floresta: Belterra, a experiência da plantation de seringa de Henry Ford na Amazônia brasileira (1934-1945) ${ }^{1}$
}

\author{
José Carlos Matos Pereira² \\ Universidade do Estado do Rio de Janeiro \\ Museu Nacional/UFRJ \\ jcpmatos@gmail.com
}

\begin{abstract}
Resumen
Este artículo examina cómo fue atraído el capital americano para la Amazonia brasileña mediante la concesión de un millón de hectáreas en la margen derecha del río Tapajós, en el estado de Pará y la exención de impuestos por un período de 50 años para la compañía Henry Ford. Estos procedimientos de gobierno fueron solicitados por el gobierno federal crearon un ambiente favorable para la instalación de la ciudad empresarial de la Compañia Ford Industrial del Brasil (CFIB) y la (re)socialización de un gran contingente de inmigrantes y brasileños en la ciudad de Fordlandia y más adelante en Belterra. Destacamos el proceso de disciplinamiento, control, formación y organización de la remuneración basado en el sistema de producción fordista. Al presentar el proyecto de civilización capitalista y los aspectos estructurantes de su racionalidad, a través del "discurso del desarrollo" usada con el sentido la inferioridad del "otro" y del vacío demográfico para justificar el proyecto de modernización capitalista en curso en el país continuado más allá de ese período.

Palabras clave: Discurso del Desarrollo - El Amazonas - El Fordismo - Ciudad-Empresa - Modos de vida.
\end{abstract}

\begin{abstract}
s
This article examines how the American capital was attracted to the Brazilian Amazon by granting one million hectares on the right bank of the Tapajós River in Pará state and the tax exemption for a period
\end{abstract}

1 Este artigo é resultado da pesquisa de doutorado intitulada: "Os modos de vida na cidade: Belterra, um estudo de caso na Amazônia brasileira", defendida no Programa de Pós-Graduação em Ciências Sociais (PPCIS), na Universidade do Estado do Rio de Janeiro (UERJ), em março de 2012, sob orientação da Prof ${ }^{\mathrm{a}}$. Márcia Pereira Leite.

2 Pós-Doutorando do Programa de Pós-Graduação em Antropologia Social (PPGAS), Museu Nacional/UFRJ, com o projeto de pesquisa: "Política, família e aparatos públicos: os modos de vida indígena e sua participação política na cidade”. Bolsista Faperj. Integrante do Núcleo de Antropologia do Trabalho, Estudos Bibliográficos e de Trajetórias (NuAT)- PPGAS, Museu Nacional, UFRJ.

MATOS PEREIRA, José Carlos, "Cidade na floresta: Belterra, a experiência da plantation de seringa de Henry Ford na Amazônia brasileira (1934-1945)", en Avances del Cesor, Año X, N 10, 2013, pp. 129-150. 
of 50 years to Henry Ford's company. These Procedures adopted by the Pará government in accordance with requests by the federal government created a favorable environment for the installation of the company town by Companhia Ford Industrial do Brasil (CFIB) and following (re) socialization of a large contingent of Brazilian migrants and foreigners in the city of Fordlandia, and later in Belterra. Its discipline, control, training and organization on a salary-compensation basis was based on the Fordist system of production. We introduce in this work the capitalist civilizational project and the structuring aspects of its rationality, through the "speech on development" that produces sense when founded on the inferiority of the "other" and the demographic void to justify the project of capitalist modernization underway in the country and forwarded beyond that period.

Key Words: Development Speech - Amazon. Fordism - Company-Towns - Lifestyles.

\section{Introdução}

A "Fala do Desenvolvimento" produz um sentido de Amazônia que a associa ao vazio sociocultural e demográfico, a uma natureza abundante e selvagem que precisa ser incorporada ao desenvolvimento nacional por meio do projeto de modernização capitalista para a região. Esse mesmo pensamento se refere às pessoas que lá vivem, pois são apresentadas como incapazes de transformar em riqueza econômica o patrimônio natural que detém. Baseados nessa premissa vários projetos econômicos e políticos sob abrigo estatal têm ganhado materialidade por intermédio da construção de hidrelétricas, rodovias, projetos de mineração e de colonização dirigida quando adotamos uma perspectiva de análise de longo prazo.

Mais recentemente, por exemplo, podemos citar o projeto de mineração da empresa multinacional canadense Alcoa, em Juruti, o monocultivo da soja nos municípios de Santarém e Belterra e todos os conflitos socioambientais que envolvem a construção da hidrelétrica de Belo Monte na região do Xingu, também no Oeste paraense. No entanto, o que nos interessa no âmbito deste artigo é tratar da grande intervenção na região que aconteceu nas décadas de 1930 e 1940. Falamos da Plantation de seringa de Henry Ford, a primeira experiência de cidade-empresa na Amazônia brasileira, conforme apresentaremos de agora em diante.

\section{A chegada do capital americano na Amazônia}

O interesse do capital americano na região do Tapajós no final da década de 1920 envolveu questões econômicas e políticas de múltiplas determinações e diversas escalas de articulação entre o capital internacional, governo brasileiro e as oligarquias da Amazônia. A economia americana, antes do crash de 1929, vivenciava um bom momento. Isto conferia à indústria automobilística um papel de destaque, já que a produção de automóveis ultrapassava 23 
milhões de unidades ${ }^{3}$. Havia, assim, uma demanda interna por borracha, além da necessidade do controle estratégico desta matéria-prima em decorrência das disputas econômicas com outras potências européias como Inglaterra, Holanda e França, no mercado internacional ${ }^{4}$.

A Amazônia vivia um período de estagnação econômica pós-boom da borracha, que vai da década de 1910 até meados da década de $1940^{5}$. Mesmo iniciativas como o Plano da Borracha, em 1912, que apresentava facilidades de isenção fiscal, acesso às terras devolutas do Estado e aos recursos naturais para o capital internacional, não foram suficientes para assegurar o sucesso desejado com o plano ${ }^{6}$.

No entanto, com a visita da missão americana para conhecer áreas da Amazônia onde pudessem desenvolver futuros projetos e com a realização de estudos de viabilidade econômica que duraram aproximadamente dois anos, esse quadro começou a mudar. A articulação do governo do estado do Pará junto ao governo federal e as ações sistemáticas feitas pelo Ministério das Relações Exteriores nos Estados Unidos foram fatores que tornaram possível a atração do capital americano para a Amazônia.

Aceitando as orientações da instância política federal, o governo do estado do Pará informou poder atender todos os "favores visados", o que foi concretizado pelo apoio dado à criação da Companhia Ford Industrial do Brasil (CFIB) ${ }^{7}$ e na doação de terras, antes mesmo da aprovação pelo legislativo estadual do termo de concessão, pelo período de 50 anos. A proposta elaborada pelo governo paraense permitiu o repasse de um milhão de hectares de terra na margem direita do rio Tapajós, localizada nos municípios de Aveiro e Itaituba, posteriormente estendida para Belterra, no município de Santarém, ambos no estado do Pará, para a empresa americana.

Dentre as cláusulas do contrato, concedia-se à CFIB o uso intensivo da natureza, com plantação de seringueiras, exploração mineral, utilização dos rios para navegação, construção de represas e açudes para a produção de energia, construção de estradas, rodovias, aeroporto, enfim, o sistema de comunicação terrestre, fluvial e aéreo, além de edifícios, fábricas, arma-

3 Em 1929, os Estados Unidos consumiam 58\% da produção mundial de borracha natural, algo em torno de 475 mil toneladas, que estavam sob controle das colônias inglesas (67\%) e holandesas (24\%), cujas plantações se localizavam no sudeste asiático. COSTA, Francisco de Assis, Grande capital e agricultura na Amazônia: a experiência Ford no Tapajós, EDUFPA, Belém, 1993.

4 Ibídem.

5 O declínio da produção e a queda dos preços são decorrentes da entrada da borracha produzida no sudeste asiático pelas colônias inglesas com melhores preços e maior produtividade. OLIVEIRA, José Aldemir; SCHOR, Tatiana, "Manaus: transformações e permanências, do forte à metrópole regional”, In CASTRO, Edna (organizadora), Cidades na floresta, Annablume, São Paulo, 2009.

6 MAHAR, Dennis, "Desenvolvimento econômico da Amazônia: uma análise das políticas governamentais", Relatório de Pesquisa IPEA/INPES, Nº 39, Rio de Janeiro, 1978.

7 Conforme o estatuto da sociedade anônima da CFIB publicado no Diário Oficial do Estado do Pará em 23/10/1927. 
zéns, hospitais, depósitos e tudo mais que se fizesse necessário. Outros direitos ainda foram concedidos à Ford, como exportar e importar produtos brutos ou industrializados, instalar núcleo de povoamento, contratar pessoas de dentro e fora da região, inclusive estrangeiros, e realizar pesquisas minerais. Dos termos do contrato, constava ainda isenção de taxas e impostos, fossem elas federais ou estaduais e o direito de desapropriação, por necessidade ou utilidade pública, das benfeitorias feitas pela empresa ao fim do termo de concessão. $\mathrm{O}$ retorno esperado com o empreendimento pelo governo estadual era de $7 \%$ do lucro líquido da empresa, sendo $5 \%$ para ele e 2\% para os municípios envolvidos, depois de 12 anos da implantação do projeto. Dessa forma, todos os componentes básicos estavam dados para assegurar a viabilidade do empreendimento: apoio estatal, solo fértil, rios navegáveis, abundância de terras disponíveis e a possibilidade de recrutamento da mão de obra barata. Tudo isto ad referendum do parlamento estadual ${ }^{8}$.

Ressaltamos que o processo de extração do látex em Fordlândia e Belterra foi diferente do implantado na Amazônia no período do boom da borracha, no final do século XIX e início do século XX, pois as relações de produção não estavam vinculadas ao sistema de aviamento ${ }^{9}$ que criava obrigações quase servis entre o seringueiro ${ }^{10}$ e o seringalista.

A CFIB implantou, em Fordlândia e Belterra, um sistema de produção baseado na constituição da força de trabalho em bases assalariadas, na plantação planejada em áreas definidas em quadras, no disciplinamento dos trabalhadores em hierarquias sociofuncionais e na construção de uma cidade na floresta ${ }^{11}$, tendo como referência o sistema fordista de produção, algo que ainda não havia sido experimentado na região.

8 Conforme constou no contrato assinado entre o governo do estado do Pará e a CFIB, datado de 21/07/1927, e ratificado pela lei no 2.292 de 03/10/1927, aprovada pela Assembléia Legislativa do estado.

9 “Aviar, na Amazônia, significa fornecer mercadoria a crédito. O 'aviador' [seringalista] de nível mais baixo fornecia ao extrator [seringueiro] certa quantidade de bens de consumo e alguns instrumento de trabalho, eventualmente pequena quantidade de dinheiro. Em pagamento, recebia a produção extrativa. Os preços dos bens eram fixados pelo 'aviador', o qual acrescentava ao valor das utilidades os juros normais e mais a margem apreciável de ganho, a título do que se poderia chamar de juros extra". SANTOS, Roberto, História Econômica da Amazônia (1800-1920), T.A. Queiroz, São Paulo, 1980, p. 159.

10 "O seringueiro, em sua maioria retirante nordestino, era o último elo da cadeia econômica. Aparentemente, era livre, mas a estrutura econômica o colocava em situação de trabalho semelhante à relação de servidão". SARGES, Maria de Nazaré, Belém: riquezas reproduzindo a Belle-Èpoque (1870-1912), Paka-Tatu, Belém, 2002, p. 79.

11 Consideramos relevante a análise de Trindade $\mathrm{Jr}$ ao distinguir o uso dos termos "cidades da floresta" e "cidades na floresta". Para o primeiro caso, Trindade Jr nos fala dos fortes enraizamentos das "cidades ribeirinhas" com o rio, o entorno, a natureza e com a característica socioeconômica e cultural local e regional. Já o termo "cidades na floresta" está associado aos nexos e exigências do 
Em seu estudo sobre o fordismo, Gramsci (1988) observa que sua racionalidade econômica exigia um novo tipo humano, adequado às novas formas de trabalho e produção, perfil este conseguido através da combinação dos mecanismos de coação e consentimento. Os primeiros podem ser realizados por meio de uma rígida disciplina e pelo controle empresarial da vida privada do trabalhador para evitar o desperdício de energia deste e como forma de não prejudicar o processo de trabalho e produção, já que o mesmo exigia um movimento repetitivo, mecânico e preciso. Em relação ao consentimento, um bom salário e a perspectiva da melhoria da condição de vida serviriam como elementos de convencimento em relação à aceitação da proposta da empresa ${ }^{12}$.

\section{A instalação da cidade-empresa em Fordlândia}

Data de 1928 a chegada da CFIB na localidade de Boa Vista, às margens do rio Cupari, posteriormente denominada de Fordlândia. Dois navios americanos trouxeram as máquinas e os equipamentos necessários para construir no lugar a cidade-empresa que seria base para a atividade de exploração da seringa na região do Tapajós. Conforme noticiou o New York Times, em 26 de julho de 1928, o navio Lake Ormoc partiu de Detroit naquele dia rumo à Santarém, no Brasil, para abastecer de suprimentos, máquinas, pessoal e equipamento, em sua primeira operação, o seringal de Henry Ford na Amazônia ${ }^{13}$. Hospitais, oficinas, casas, escolas, cinemas, estradas, serraria, depósitos, restaurante, campo de futebol, igreja, sistema de abastecimento de água e energia, ferrovia, dentre outros, constituíram a infraestrutura erguida pelo empreendimento americano.

A CFIB promoveu o recrutamento de mão de obra dentro e fora da região. Eram migrantes nordestinos - principalmente cearenses, mas tinha paraibanos e pernambucanos, além de baianos e potiguares- e de outras regiões, como os mineiros e pessoas oriundas da Amazônia, como aquelas residentes nas proximidades dos rios Tapajós, Arapiuns, Amazonas

mercado nacional e internacional demandante de matéria-prima, uma vez que estas se caracterizam por ser base dos grandes projetos que se instalam na região para a exploração econômica da madeira, minério e fragrância, por exemplo. E, por serem objetos artificiais, transformam-se em enclaves urbanos à medida em que negam a forma de organização socioespacial e cultural local e regional. TRINDADE JR, Saint-Clair Cordeiro da, "Cidades na floresta: os 'grandes objetos' como expressões do meio técnico-científico informacional no espaço amazônico", in Revista IEB, São Paulo, 2010, No 30, pp. 113-137.

12 GRAMSCI, Antônio. Maquiavel, a política e o Estado moderno, Civilização Brasileira, Rio de Janeiro, 1988.

13 New York Times, 27/07/1928. Ford Rubber Plantation Ship Leaves Detroit; Will Set Up Base on 6,000,000 Acre Tract. <http://select.nytimes.com> [Consulta: 23 agosto 2010]. 
e Lago Grande ${ }^{14}$. O grupo dos estrangeiros, minoritário, era constituído por holandeses ${ }^{15}$, italianos, russos, japoneses, chilenos, chineses, peruanos, portugueses, alemães, ingleses, dinamarqueses, suecos, austríacos, franceses, australianos, suíços, barbadianos e sul-africanos e compunham o quadro sociofuncional, formado por técnicos especializados e peões, cuja direção estava sob coordenação americana que, em 1929, beirava quase 3.000 trabalhadores, conforme relatos colhidos em campo.

As atividades profissionais, em Fordlândia estavam divididas em 26 seções: oficinas de máquinas a vapor, carpintaria, eletricidade, pintores, usina central, encanadores, serraria, garagem, marinha, armazéns, estivadores, pecuária, hoteleiros, médicos e enfermeiros, cozinheiros e copeiros, higiene, capatazes e apontadores, escritório, estradas, serviços gerais, brocas e derrubadas, capinação, plantação, extratores de lenha para a usina, dentre outros diversos trabalhos e trabalhadores ${ }^{16}$.

A Companhia convocava trabalhadores para as plantações também através dos anúncios em jornais, onde prometia $\mathrm{Cr} \$ 9,00^{17}$ por dia para trabalhadores em geral e $\mathrm{Cr} \$ 6,00$ para trabalhadoras. Oferecia gêneros alimentícios (farinha, arroz, feijão, açúcar, charque, carne fresca, banha, manteiga, café e leite condensado) a preços baixos. Para os seringueiros, em Fordlândia, pagava Cr\$11,00 por dia e, em Belterra, CR\$10,00 para seringueiros enxertadores. Comprometia-se em dar creche, moradia, escola, uniforme e material escolar para os filhos dos empregados, assistência médica, hospitalar e dentária para toda família ${ }^{18}$.

Muitas famílias de trabalhadores vieram de Fortaleza (CE), mas foram recrutadas em hospedarias de Belém (PA). Um de nossos entrevistados, o senhor Tica ${ }^{19}$, hoje com 74 anos de idade, veio para Belterra com seus irmãos seguindo o sonho do pai, funcionário público, de virar seringueiro e ficar rico.

Eu vim parar aqui porque meu pai, ele tinha muita vontade de ser seringueiro, cortar seringa no Acre, né. Naquele tempo, o Acre era o eldorado do cearense, muito cearense vinha pra cá, pro Acre, trabalhava um ano e voltava pra lá com dinheiro e o povo ficava, né, ouriçado com aquilo e vinha mais e mais, e mais, e papai era um desses

14 AMORIM, Antônia Terezinha dos Santos, A dominação norte-americana no Tapajós, Thiagão, Santarém, 1995, SENA, Cristovam, "Fordlândia: breve relato sobre a presença americana na Amazônia”. In Cadernos de histórias da ciência, São Paulo, 2008, V. 4, N² 2, pp. 90-107.

15 Como é o caso de J.J.A.F. Reukema, nascido em Haya (Holanda), em 1894 e contratado pela CFIB, aos 45 anos de idade, em 1937. Deixou mulher e filhos no país de origem, mas foi desligado em setembro de 1939, conforme consta no registro de empregado da empresa.

16 COHEN, Jacob. Fordlândia: a grande interrogação do futuro, Belém, 1929.

17 Até 1942, a moeda brasileira era o mil-réis. A partir de então, passou a ser o cruzeiro.

18 Jornal de Santarém, 30/10/1943.

19 Francisco Bezerra Oliveira (Tica), 73 anos, ex-cozinheiro do Hospital Henry Ford, entrevista realizada em outubro de 2009.

\section{4}


incutido com essa vida. Inclusive ele não tinha menor necessidade de vir, porque ele era funcionário público lá, mas ele, era o desejo dele, era um sonho de vir pro Acre. Então, ele reuniu a família que já era de seis filhos, onde eu já tinha seis anos e veio aos trancos e barrancos com a passagem grátis que o governo dava devido à seca.

Apesar dos altos investimentos, no valor de 20 milhões de dólares, o projeto fracassou em Fordlândia, em 1934 ${ }^{20}$, e depois em Belterra, no ano de 1945. Dentre os fatores que contribuíram para esta situação, podemos citar: o atraso nas operações, a má escolha da localização do empreendimento e o "mal das folhas", doença que atacou os seringais" além da forma acidentada do terreno para o desenvolvimento do cultivo da seringueira, o distanciamento do projeto em relação a cidade de Santarém (lugar de concentração da mão de obra disponível) e a dificuldade de navegação dos navios maiores durante o período da estiagem $^{22}$.

\section{A mudança da Plantation para Belterra}

Com o intuito de superar o fracasso experimentado em Fordlândia, quando mudou para Belterra a CFIB realizou a plantação em áreas mais planas, importou um novo tipo de seringueira e usou enxerto nas mudas para torná-las mais resistentes às pragas. Construiu um porto em águas mais profundas e se localizou mais próxima da cidade de Santarém para facilitar o recrutamento da mão de obra. Permitiu que terceiros pudessem explorar na cidade a oferta de serviços, como bar, sapataria, padaria e barbearia e montou a comissária (pequeno comércio) para ofertar produtos alimentícios mais baratos na cidade. Seus funcionários também poderiam desenvolver, em seus lotes de moradia, atividades ligadas à agricultura e criação de animais de pequeno porte.

Argumentamos que os procedimentos adotados pela CFIB sob o abrigo da "Fala do Desenvolvimento" e da ação estatal também podem ser explicados pelas análises de Santos (2008), quando este observa que a prática humana como racionalidade econômica capitalista sob hegemonia do grande capital e do Estado impõe usos do espaço alheios à sua gente e ao lugar. São construtos artificiais fabricados que dão novas funcionalidades ao preexistente sob o domínio da técnica e da informação. Esta ação direcionada tem no discurso do saber

20 Data de $04 / 05 / 1934$ a assinatura do termo de permuta que concedeu novas terras para serem exploradas pela CFIB com a extensão de 281.500ha (duzentos e oitenta e um mil e quinhentos hectares), denominada de Belterra, conforme termo aditivo assinado entre o governo do estado, representado no ato pela Diretoria Geral de Obras Públicas, Terras e Viação, e a CFIB, por intermédio de seu Diretor-Gerente, Archibald Johnston.

21 SENA, Cristovam, "Fordlândia..." Op. Cit.

22 CRULS, Gastão, "Impressões de uma visita à Companhia Ford Industrial do Brasil", in Revista Brasileira de Geografia, № 4, São Paulo, 1939, pp. 3-22. 
competente a sua base de legitimação. É o que Santos chama de espaço usado, resultante dos sistemas de objetos, sistemas de ações e discurso. Sob essa lógica imposta e externa, os lugares cumprem papéis econômicos na acumulação do capital. Sua solidariedade organizacional pode ser explicada pelos nexos de verticalidade, que diz respeito à circulação, distribuição e consumo entre os lugares separados e assegura o funcionamento global da sociedade e da economia ${ }^{23}$.

Como veremos a seguir, trata-se de um conjunto de transformações materiais e simbólicas impostas pelo sistema fordista de produção, visto que aqueles trabalhadores não detinham as condições técnicas para o desenvolvimento da atividade industrial. Dessa forma, o treinamento pontual e fragmentado, produziu transformações radicais no âmbito da experiência e da prática daqueles indivíduos: um tipo de "transmissão de conhecimento prático e específico de um ethos capaz de assegurar o êxito da atividade econômica". Temos assim, para fins de novos parâmetros de organização da vida social do lugar o "patrimônio objetivado de outra civilização" (grifo nosso), alheio e externo à sua formação sociocultural primeira. É a universalização das trocas monetárias do mundo urbano que converte o dinheiro em necessidade universal e absoluta ${ }^{24}$.

\section{A construção da cidade-empresa em Belterra}

Para viabilizar a produção foi necessário construir uma cidade na floresta nos moldes das cidades-empresa já experimentadas nos Estados Unidos. Na Amazônia, surgia uma cidade com estradas que margeavam as quadras de seringueiras; casas residenciais para o respectivo quadro funcional; abastecimento de água e energia elétrica; venda de produtos de primeira necessidade; hospital e escolas de ensino primário; galpões onde funcionavam a marcenaria e a oficina mecânica; telefone e guaritas de segurança; caminhões e tratores; portos e trapiches para o embarque e desembarque de pessoas, mercadorias, ferramentas, máquinas e equipamentos; clube e praça para a prática de esportes.

Contudo, chamamos atenção que as terras doadas pelo governo do estado para a CFIB era habitada e que a ideia de vazio demográfico contido na "Fala do Desenvolvimento" não corresponde a realidade. Na localidade de Irussanga em Belterra, ainda hoje vivem 19 famílias que são descendentes daqueles grupos sociais que já habitavam a região antes da chegada dos americanos. São famílias que vivem da caça (veado, paca, cutia, tatu), da pesca (pescada, chaperema, aracu, jaraqui, tucunaré), da produção de mandioca (farinha e tapioca), da plantação de muruci, taperebá, da extração do caju e da torrefação de sua castanha, esta última vendida aos visitantes das praias e igarapés nos fins de semana. Socorro, outra

23 SANTOS, Milton, Técnica, espaço, tempo, EDUSP, São Paulo, 2008.

24 BOURDIEU, Pierre, Argélia 60: estructuras econômicas y estructuras temporales, Siglo Veintiuno, Buenos Aires, 2006, pp. 33, 37. 
de nossas entrevistadas, esclarece que as "famílias tradicionais não são os indígenas ou quilombolas, mas os descendentes destes que vivem em uma comunidade há muito tempo, meu avô, minha avó, meu pai, minha mãe". Segundo seu pai, de 71 anos de idade, em 1926, por lá já viviam oito famílias parentes, como tias e avós. "Antes mesmo da Ford vir para Belterra, já existiam os moradores da área". Não só lá, mas na comunidade de Porto Novo também moravam alguns parentes dele. "Meu pai me contou que minha avó contou para ele, que veio morar pra cá em 12 [1912], porque o marido dela era músico e eles andavam de canoa nas comunidades tocando" 25 .

Costa, que desenvolveu detalhada análise dos documentos internos da Companhia, identificou dois movimentos estratégicos por ela desenvolvidos. Primeiro expropriou a terra das famílias que moravam dentro da área da concessão da Ford, por meio do pedido junto ao governo paraense, de que este efetivasse a indenização e efetuasse a retirada das famílias. Segundo, como resultado do primeiro, visava transformá-los em trabalhadores assalariados subordinados à empresa. Sabendo que só expropriá-los da terra não era suficiente para transformá-los em assalariados, Johnston, diretor geral da empresa, negociou com seus dirigentes nos Estados Unidos para implantar outras formas de usos da terra, criando obrigações e deveres para os agricultores que fossem favoráveis à Companhia, para que tanto trabalhassem na limpeza e manutenção dos seringais, quanto se comprometessem a produzir alimentos que seriam comprados por ela ${ }^{26}$.

Isto representa a destruição dos modos de $v^{2} \operatorname{lda}^{27}$ preexistentes para que novas modalidades produtivas pudessem ser instaladas. Assim, o valor de troca se sobrepunha ao valor de uso ${ }^{28}$ e o tempo lento da vida pretérita ganhava nova velocidade e dinâmica, aquela exigida pelo trabalho sistemático e repetitivo, para a produção de seringa que, de Belterra, devia alcançar o mercado mundial e, particularmente, servir de matéria-prima à indústria automobilística norte-americana.

25 Socorro, 43 anos, artesã. Entrevista realizada em outubro de 2009.

26 COSTA, Francisco, $O$ grande capital..., Op. Cit.

27 Ressaltamos que os modos de vida estão relacionados aos hábitos, condutas, técnicas e instituições adquiridos por herança cultural ou desenvolvidos localmente. Dessa forma, envolvem as formas de produção da existência e a satisfação de necessidades imediatas e duradouras (relações com a natureza, técnicas usadas para adquirir e produzir alimentos, construir moradia e vestuário, as preferências alimentares etc.) e as relações de sociabilidade. CÂNDIDO, Antônio, Parceiros do Rio Bonito, Duas Cidades, São Paulo, 1971.

28 O valor de uso está relacionado ao trabalho realizado para a transformação da natureza a fim de satisfazer as necessidades de subsistência do grupo. $\mathrm{O}$ valor de troca, por sua vez, refere-se ao trabalho humano que dedica certa quantidade de tempo para produzir mercadorias que sejam intercambiáveis monetariamente, no qual o dinheiro é o equivalente geral e o mediador dessas relações. MARX, Karl, Contribuição à crítica da economia política, Martins Fontes, Rio de janeiro, 1983. 
Em sua análise sobre o Fordismo, Harvey ${ }^{29}$ indica que:

A produção [em] massa significava consumo [em] massa, um sistema de reprodução da força de trabalho, uma nova política de controle e gerência do trabalho, uma nova estética e uma nova psicologia, em suma, um novo tipo de sociedade democrática, racionalizada, modernista e populista.

Contudo, observamos que em Belterra e Fordlândia não existiu a "tecnologia da linha de montagem para a produção de massa", nem consumo de massa, conforme analisou Harvey ${ }^{30}$, mas um estágio anterior e fundamental para esse momento, a produção de matéria-prima para a indústria automobilística. Nem a proposta de cinco dólares se tornou realidade, já que os dirigentes da Companhia, em Fordlândia, propunham como pagamento entre $25 \mathrm{e}$ 50 centavos de dólares por dia trabalhado ${ }^{31}$.

Com efeito, em Belterra, as relações capitalistas não se implantaram no 'intramuros' de uma fábrica de automóveis ${ }^{32}$, mas no chão da floresta e por entre os rios de uma cidade-empresa com base no sistema fordista de produção, readaptado ao ser implantado na Amazônia.

A criação da cidade-empresa foi a estratégia usada pelo capital diante de situações onde a oferta de infraestrutura e serviços urbanos era precária e não dava suporte para $o$ desenvolvimento das atividades industriais. Essa estratégia se mostrou importante tanto para o processo de reprodução do capital como para a concentração e controle da força de trabalho, através da oferta de moradia para os trabalhadores das empresas ${ }^{33}$.

\section{Os modos de vida na cidade}

Recorremos aos velhos, os guardadores da memória da vida do lugar ${ }^{34}$. Aqueles que ainda vivem na cidade de Belterra e podem nos contar, a partir de sua experiência e das lembranças, como foi a vida social naquele período. Vejamos primeiro o repente do migrante e poeta nordestino que chegou ainda criança, aos 7 anos de idade na região.

Em maio de 34, assim dizia a folhinha, e o povo da ribeirinha sempre tão acomodado, vendo o navio estrangeiro encostando sorrateiro ficou bastante assustado. Um corsário, um viajante ou um simples comandante querendo comprar comida. Mas o que nin-

29 HARVEY, David, Condição pós-moderna, Loyola, São Paulo, 1992, p. 121.

30 Ibídem.

31 GRANDIN, Greg, Fordlândia: ascensão e queda da cidade esquecida de Henry Ford na selva, Rocco, Rio de Janeiro, 2010.

32 VIANNA, Luiz Werneck, Liberalismo e sindicato no Brasil, Paz e Terra, Rio de Janeiro, 1978.

33 PIQUET, Rosélia, Cidade-empresa: presença na paisagem urbana brasileira, Zahar, Rio Janeiro, 1998.

34 BOSI, Ecléa, Memória e sociedade: lembranças de velhos, T.A. Queiroz, São Paulo, 1979.

\section{8}


guém sabia é que o gringo trazia para o lugar nova vida. No mesmo dia, o estranho, com entusiasmo tamanho fincou um marco na terra, depois com a demarcação veio a denominação Plantações Ford de Belterra. Em pouco mais de dois anos, os nobres americanos tinham um trabalho perfeito, para sua agricultura montaram infraestrutura pra ninguém botar defeito, fizeram muitas estradas, muitas casas e moradas para compor o sistema, e o movimento crescia chegando assim todo dia muita gente num só lema, trabalhar, ganhar dinheiro era o anseio verdadeiro de todos que aqui chegavam. Variadas profissões entre técnicos e peões certamente se empregavam, e assim o seringal crescia de maneira tal que assustou as nações. Em toda parte se via planta de dupla enxertia aos milhares e aos milhões. Feliz se reunia o povo e ia ao Porto Novo, para no fim de semana, fazer compra, namorar ou simplesmente tomar um trago de boa cana. Com o serviço hospitalar e também o escolar e ao ar livre o cinema, com creche para os guris, se vivia bem feliz, a vida era sem problema ${ }^{35}$.

Os relatos indicam que o projeto começou em Porto Novo, que fica distante cerca de 12 $\mathrm{km}$ de onde é hoje a sede da cidade. Lá os americanos fizeram a acampamento provisório com médico, almoxarifado e hospital. O recrutamento da mão de obra se fazia por meio de uma embarcação da empresa que saia pelos rios Tapajós, Arapiuns, Amazonas e Lago Grande, procurando pessoas nas vilas que quisessem vir trabalhar em Belterra. Faziam alistamento e lotavam a embarcação. Outros trabalhadores foram deslocados de Fordlândia para Belterra.

Os recrutados eram ribeirinhos, pescadores e agricultores acostumados com outra forma de vida, do tempo lento, da pesca, da agricultura e da colheita de frutos da floresta. Muitos deles ainda adolescentes com idade entre 13 e 17 anos $^{36}$. Outros vinham de cidades importantes como Manaus (AM), Belém (PA) e de municípios vizinhos.

O senhor Pedro, hoje com 80 anos de idade, veio do Lago Grande, em Santarém, para estudar, já que seu pai se empregou na Companhia em 1934. Com a morte do pai, em 1939, quando ele tinha 9 anos de idade, a família passou por grandes dificuldades. Narra ele que, ainda menino, aos 12 anos de idade, trabalhava na limpeza das quadras de seringa e no plantio da semente para a produção de mudas. Aos 15 anos, foi para o enxerto e, aos 16 anos, para a estação de tratamento do látex e, aos 17 anos, para o corte da seringa ${ }^{37}$.

35 Tica, poeta, compositor e repentista. Cearense, 74 anos, ex-cozinheiro do Hospital Henry Ford. Transcrição do depoimento contido em vídeo sobre o relato da experiência de elaboração do Plano Diretor Participativo de Belterra. Federação de Órgãos para Assistência Social e Educacional (FASE), 1997.

36 Cerca de 60 "garotos" trabalhavam nas plantações desenvolvendo tarefas consideradas fáceis como podagem, inspeção de pestes e lagartas e enfermagem. JOHNSTON, Archibald, Relatório sobre as plantações de borracha em Fordlândia e Belterra, tradução de NOGUEIRA, Antônio Frapuan Sena, s/d., p. 26.

37 Pedro Afonso Batista, 80 anos, ex-seringueiro. Nascido no Lago Grande, município de Santarém. Entrevista realizada em março de 2011. 
Depois da chegada ao acampamento, eles eram deslocados para a cidade a fim de realizar exames médicos, formalizar a relação de trabalho, ser fotografados e se integrar ao processo de produção em curso.

\section{A organização do espaço urbano}

Rapidamente a floresta foi derrubada para a abertura das estradas com a ajuda de tratores, correntes, machados, terçados e serrotes de duas pontas. Também foram preparadas as quadras para plantar as mudas de seringueiras e construídas as casas onde iriam morar americanos, funcionários e para instalar os escritórios da empresa. A madeira retirada, como a castanheira, o cedro, a itaúba e jarana, por exemplo, foi aproveitada para construção das casas e mobílias, mas o acampamento continuou recebendo as pessoas que, de lá iam por meio de condução para a cidade se apresentar ao trabalho.

O cercado, onde funciona hoje a Secretaria Municipal de Infraestrutura/SEMINF, era o posto fiscal de alistamento dos trabalhadores e o espaço onde os americanos montaram a oficina mecânica, a garagem, a marcenaria e a carpintaria. Lá montaram as máquinas, a comissária que, segundo o senhor Erasmo, era o comércio para vender mercadorias vindas de São Paulo, Rio de Janeiro e Belém para os funcionários a preço mais baixo.

As imagens apresentadas, datadas das décadas de 1930 e $1940^{38}$ representam os lugares da memória ${ }^{39}$, o plano de referência material que ancora as lembranças do período onde a vida social se realizava. Na figura 1, podemos observar: 1) as casas da Vila Timbó, onde moravam os funcionários do hospital (no lado direito ao alto); 2) a praça circular onde os americanos jogavam golfe; em frente, 3 ) os galpões, onde se fazia o alistamento dos trabalhadores; lá também funcionavam as oficinas. Por fim, ao lado direito da praça, 4) a Igreja Católica de Santo Antônio e seu respectivo salão paroquial; do lado esquerdo da praça, 5) a Igreja Batista.

38 As fotos de época utilizadas neste trabalho foram gentilmente cedidas pelo senhor Osvaldo Teixeira Góes, engenheiro da Companhia na década de 1940, hoje aposentado e residindo, em Brasília, no Distrito Federal.

39 POLLAK, Michael, "Memória e identidade social”, Estudos Históricos, № 10, São Paulo, 1992, V. 5, pp. 1-15. 


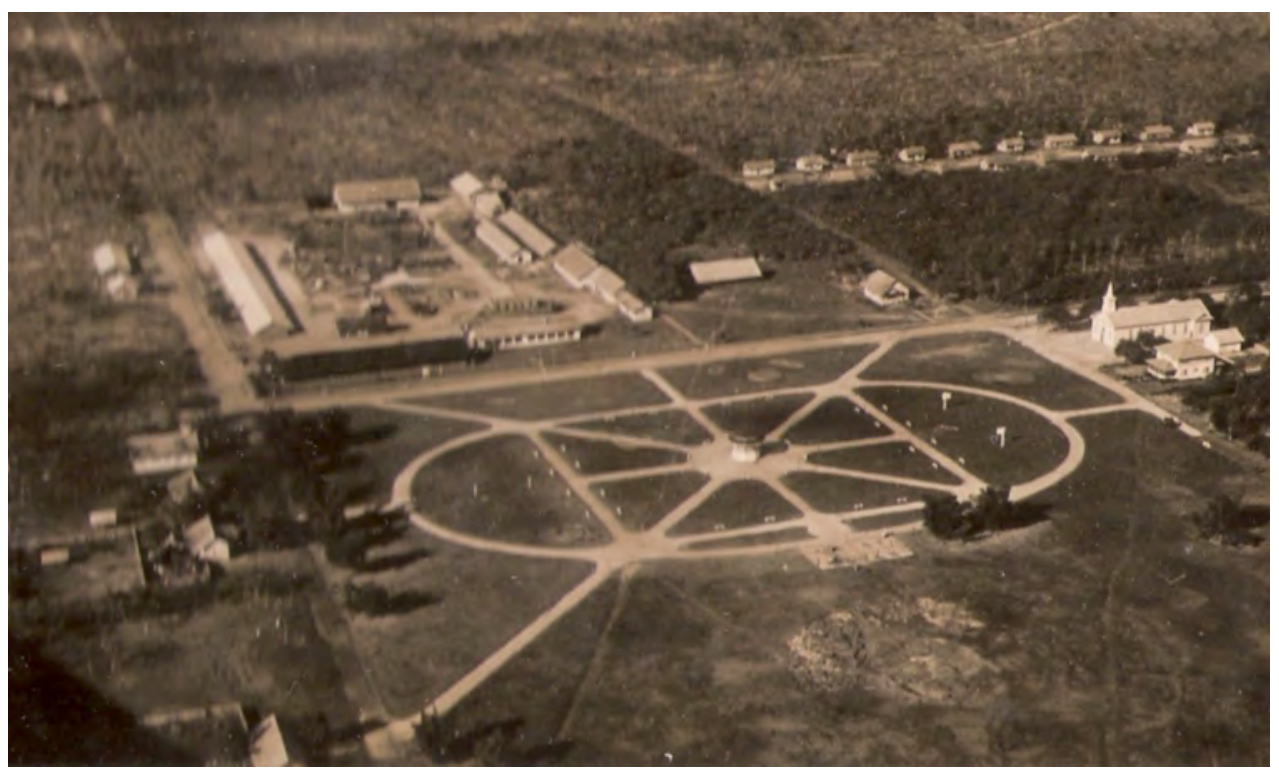

Figura 1: Visão panorâmica da infra-estrutura criada pela CFIB.

Foto: Arquivo pessoal de Osvaldo Góes, 1937.

Nas proximidades da cidade, foi construído o campo de aviação para dar suporte ao projeto. Ele assegurava o deslocamento sistemático de passageiros e o transporte de mercadorias vindas de outras regiões para a cidade. Também construíram estradas, casas para os funcionários, sistema de iluminação, galpões, a creche, onde as mães deixavam as crianças durante o expediente de trabalho e o escritório da companhia (figura 2). 


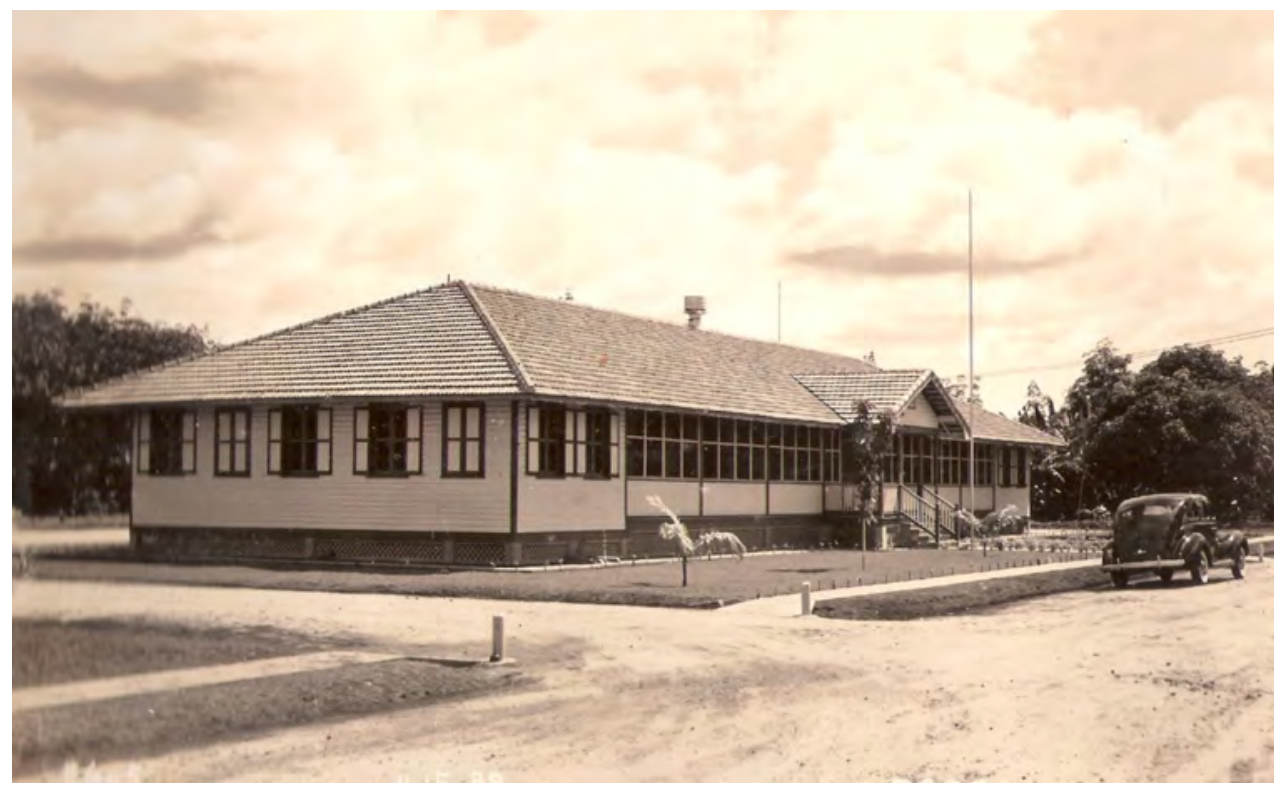

Figura 2: Escritório da CFIB.

Foto: Arquivo pessoal de Osvaldo Góes, 1939.

Nas proximidades da Vila Americana foi construído o Hospital Henry Ford que se tornou uma grande referência na área de saúde na Amazônia por seus equipamentos e corpo profissional especializado. Nas imediações, também ficava o hotel onde se hospedavam os funcionários, principalmente aqueles vindos de fora e a casa dos médicos.

Somados a infraestrutura criou-se uma hierarquia funcional de técnicos especializados e peões sob coordenação americana, bem como ocorreu a distribuição espacial das moradias e dos indivíduos segundo sua utilidade ${ }^{40}$ por meio das vilas Americana, Mensalista, Operária, Timbó, Viveiros I e II e Pequiá; do alojamento dos solteiros e das cabanas dos seringueiros e campeiros ${ }^{41}$.

40 FOUCAULT, Michel, Vigiar e punir, Vozes, Rio de Janeiro, 1977.

41 Documentos internos da companhia indicam que, por volta de 1941, se tinha construído 844 casas, sendo que desse total, 758 eram de palha. Isto representava cerca de $90 \%$ do total das construções, e eram destinadas aos homens casados. Para os solteiros foram construídos 8 alojamentos de palha e 7 alojamentos permanentes, para a acomodação de 960 homens. A Vila Americana era composta de 5 casas, 1 clube e uma casa para solteiros. Tinha 2 casas para os médicos e 17 para os funcionários do hospital (Vila Timbó), 33 casas para gerentes e trabalhadores (Vilas Mensalista e Operária). Destas 10 casas eram para 2 famílias cada (Vila Viveiros) e, em construção, 52 casas duplas permanentes, 
A Vila Americana, a primeira a ser construída na cidade, tinha um conjunto de casas onde viviam os americanos que coordenavam o projeto. O senhor Erasmo relata que as principais atividades de lazer dos americanos eram o golfe jogado todo o dia de domingo na praça central da cidade, as festas no Club House para ouvir música e beber uísque, e o jogo de sinuca num bar de propriedade de um italiano, de nome Simão Gonzalez, que teve autorização da empresa para, numa das casas, desenvolver essa atividade na cidade. Para os padrões mais exigentes da vestimenta norte-americana tinha um alfaiate, de origem sul-africana, que fazia os paletós, calças e outros acessórios ${ }^{42}$.

Essas atividades eram restritas ao staff americano, assistidas de longe pelo conjunto de trabalhadores da Companhia. No máximo, os jovens podiam, no caso do golfe, carregar as sacolas contendo tacos e bolas, pelo qual recebiam o valor de cinco mil réis no final das partidas como remuneração pelo trabalho realizado. No domingo, por volta das oito horas da manhã, os americanos chegavam em seus carros, vestidos de branco e chapéu, com sacos de golfe e estacionavam na praça. Jogavam até as três horas da tarde, um esporte que só eles conheciam, relata nosso entrevistado.

A premissa de "industrializar a selva" que movia a racionalidade norte-americana não condizia com uma relação que se desse com base na alteridade. Ao contrário, essa perspectiva serviu para naturalizar a diferença e as hierarquias sociais entre "superiores" e "inferiores" tendo como referência o anúncio do estereótipo. Na situação analisada por estes autores, a diferença entre os estabelecidos e os outsiders referia-se ao tempo de residência na cidade, entre os mais antigos e os recém-chegados, respectivamente. Em Belterra, a situação se inverte: os "de fora" são os estabelecidos e "os dentro", os outsiders, e questões como nacionalidade, cor, condições de moradia, profissão, salário, nível de renda e de escolaridade eram os elementos constitutivos e demarcadores das diferenças entre eles ${ }^{43}$.

$\mathrm{Na}$ Vila Mensalista, moravam os trabalhadores com cargos de chefia, principalmente em atividades de administração; outros que trabalhavam no hospital, como o farmacêutico; e os russos que faziam o trabalho de autópsias, ou seja, os trabalhadores mais especializados. Na Vila Operária, moravam trabalhadores com alguma especialização, como mecânicos, marceneiros, carpinteiros, torneiros e os tratoristas.

$\mathrm{Na}$ Vila Viveiros I e II, moravam os trabalhadores que cuidavam das mudas de seringueiras. Na Vila 129, viviam os trabalhadores que desenvolviam atividades braçais no projeto.

uma igreja, um galpão, uma escola e área com bosque na Vila 129. No total, naquele período, com as novas construções, as casas somavam 896 prédios. JOHNSTON, Archibald. Relatório..., Op. Cit. 42 Erasmo Moura, 79 anos, nascido em Fordlândia, ex-seringueiro. Entrevistas realizadas em outubro e novembro de 2009 e março e abril de 2011.

43 ELIAS, Norbert; SCOTSON, John L, Os estabelecidos e os outsiders: sociologia das relações de poder a partir de uma pequena comunidade, Zahar, Rio de Janeiro, 2000. 
Disse-nos o senhor Antônio ${ }^{44}$, um ex-seringueiro e morador da vila, que lá moravam as pessoas que trabalhavam nos seringais, como ele e sua esposa, por exemplo.

Nas proximidades da Vila Mensalista, localizavam-se dois dos alojamentos onde ficavam os rapazes solteiros, que dormiam em redes, tinham o serviço de limpeza do local mantido por um zelador da empresa e não pagavam aluguel pela hospedagem.

A categoria mais baixa na hierarquia sociofuncional da empresa, os campeiros e seringueiros, não morava em casas com o padrão de vila, mas em casa de palha ao longo das estradas, com piso de chão, sem água, luz ou telefone (figura 3).

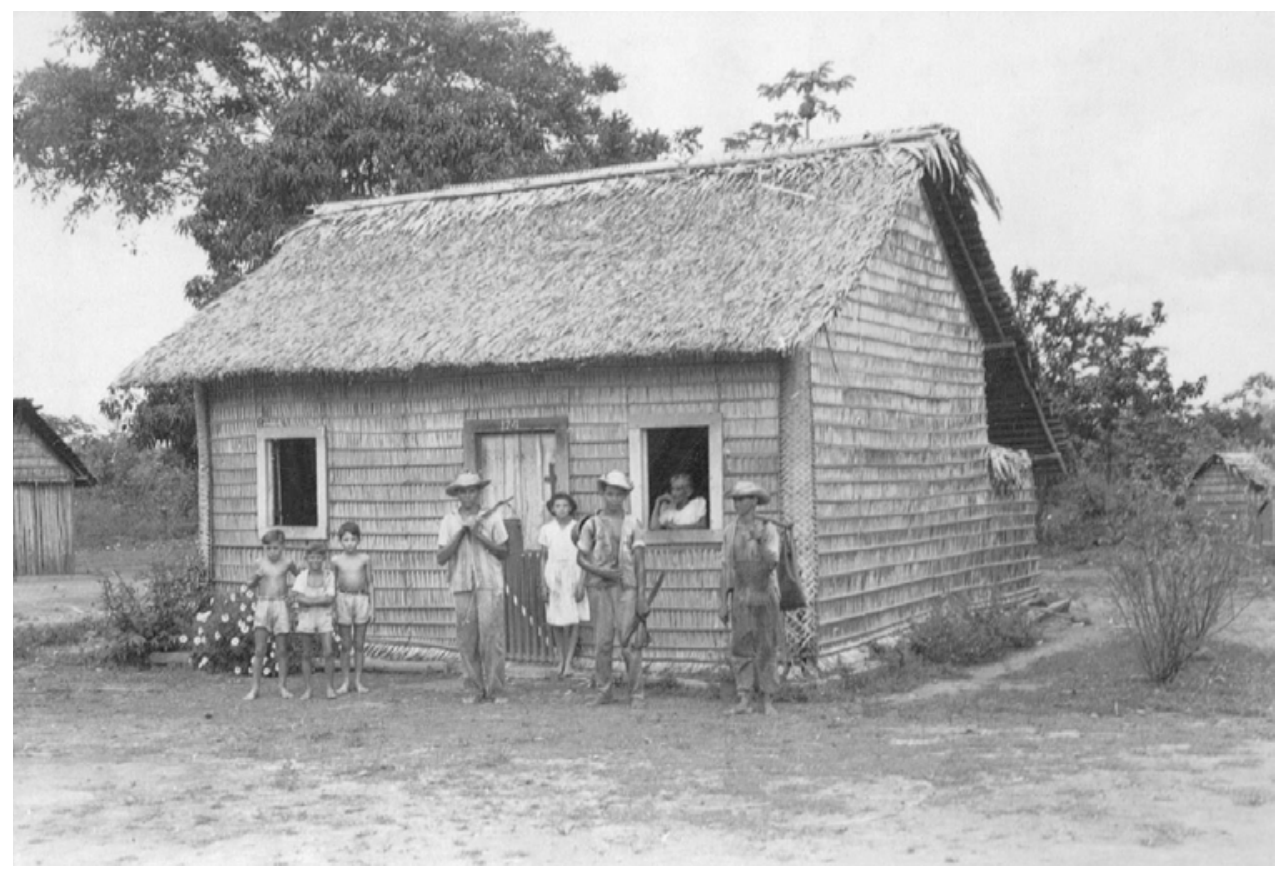

Figura 3: Casa dos Seringueiros. Belterra, 1953.

Fonte: IBGE. Disponível em: <http://biblioteca.ibge.gov.br/visualizacao/fotografias/GEBIS>. [Consulta: 25 abris 2011].

44 Antônio Delgado, 78 anos, ex-seringueiro. Nascido em Belterra em 1933. Entrevista realizada em março de 2011. 
Agora apresentaremos os mecanismos de disciplinamento e controle da mão de obra, condição básica para a formação do novo tipo humano exigidos pelo sistema fordista de produção.

\section{A disciplinarização da força de trabalho}

As 473 quadras do projeto tinham 16 hectares cada, eram margeadas por 10 estradas com até $10 \mathrm{~km}$ de extensão e foram sistematicamente plantadas. No sentido norte-sul, as de número impar (1, 3, 5, 7 e 9), e as pares no sentido leste-oeste $(2,4,6,8$ e 10). Cada capataz tomava conta de uma turma de até 150 trabalhadores. Às 6h30min, os trabalhadores já estavam enfileirados esperando a sirene tocar para iniciar o trabalho. O intervalo para o início da alimentação era às $11 \mathrm{~h}$ e o retorno ao trabalho às $11 \mathrm{~h} 30 \mathrm{~min}$. $\mathrm{O}$ fim do turno de trabalho era às $15 \mathrm{~h} 30 \mathrm{~min}$. A comida trazida pelos seringueiros (farofa de ovo) era guardada numa latinha que ficava pendurada no cós do cinturão que se prendia à calça. $\mathrm{O}$ rigor no horário e o cumprimento das metas de trabalho eram diariamente averiguados, conforme relato de vários entrevistados.

Segundo o senhor Erasmo, o primeiro apito tocava às $5 \mathrm{~h} 30 \mathrm{~min}$, para que a primeira turma acordasse e se dirigisse às plantações. Eram os campeiros e seringueiros. Geralmente cumpria-se oito horas de trabalho por dia e trabalhava-se no sábado em meio expediente. Mas havia uma variedade de horários de acordo com as atividades desenvolvidas pelos funcionários. Os enfermeiros do hospital entravam no trabalho às $6 \mathrm{~h}$ e saiam às $14 \mathrm{~h}$; os mecânicos, eletricistas, torneiros e marceneiros, que trabalhavam no cercado, iniciavam seu turno às $7 \mathrm{~h}$, e tinham uma hora para ir a casa almoçar e retornar ao trabalho. $\mathrm{O}$ segundo período se estendia até $16 \mathrm{~h}$.

A figura 4 apresenta um grupo de seringueiros durante a jornada de trabalho em Belterra ${ }^{45}$.

45 Observamos que a imagem apresentada corresponde a uma tentativa de aproximação com o contexto da época, uma vez que nessa data o projeto já estava sob coordenação do governo brasileiro. 


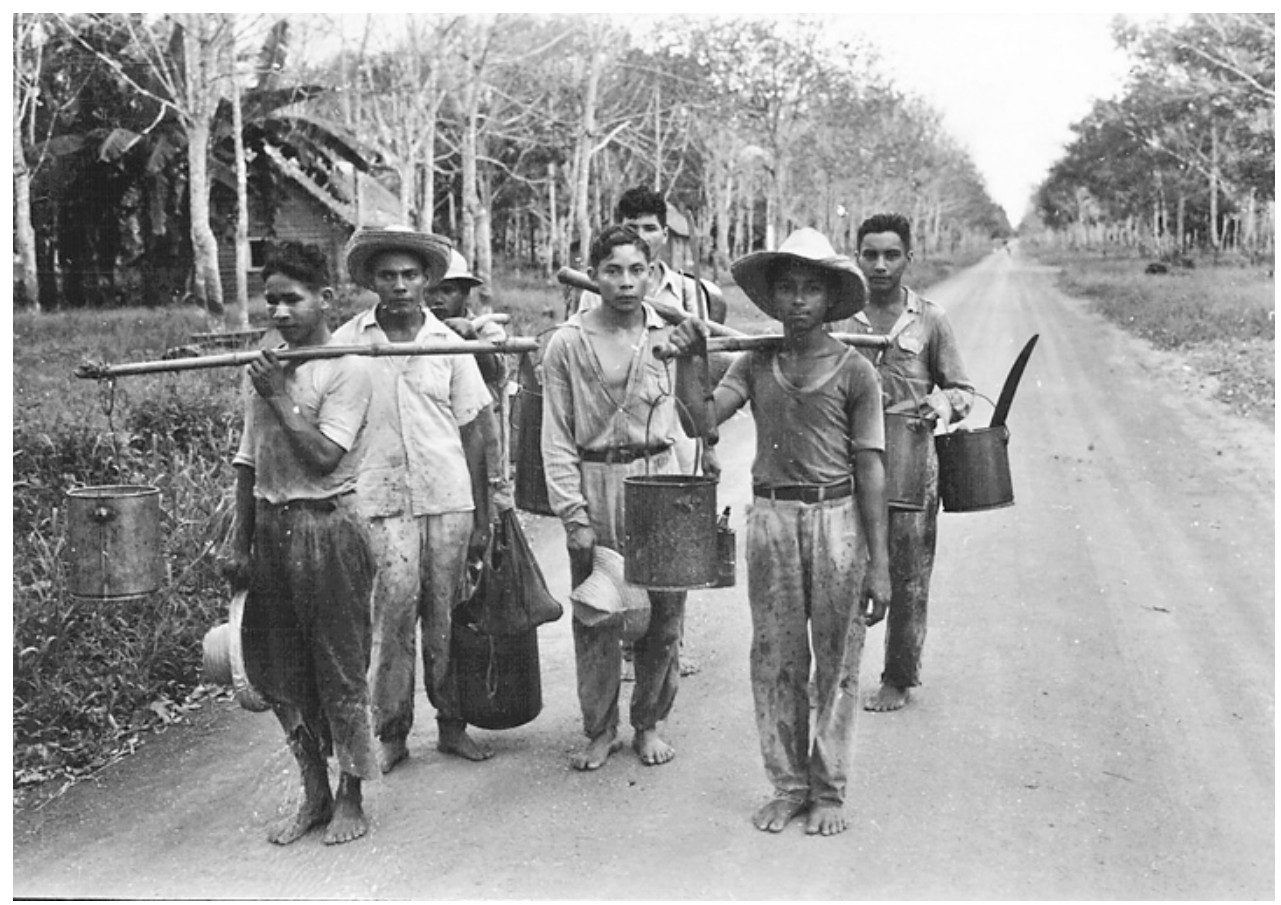

Figura 4: Seringueiros durante a jornada de trabalho. Belterra, 1953.

Fonte: IBGE. Disponível em: <http://biblioteca.ibge.gov.br/visualizacao/fotografias/GEBIS>.

[Consulta: 25 abrís 2011].

O controle desses trabalhadores era realizado pelo apontador, que controlava a presença no serviço por meio da anotação da numeração contida em uma placa de metal recebida no momento da contratação e que ficava pendurada no peito do funcionário durante toda a jornada de trabalho.

Dona Inocência, hoje com 90 anos e morando em Belém $(\mathrm{PA})^{46}$, relembra dos tempos em que trabalhava na plantação de seringa de Belterra. Fala do açougue que fornecia a carne, da farofa de carne que muita gente colocava na lata e pendurava na cintura, das aguadeiras que forneciam água para os trabalhadores durante a jornada de trabalho. Na hora do almoço, "quando a sirene tocava 11h, largava tudo. Os fiscais, "os americanos ficavam de olho pra saber se a gente estava obedecendo às ordens deles".

46 Agradecemos à Prof ${ }^{a}$. Rosa Acevedo (NAEA/UFPA) que nos autorizou a usar a entrevista feita por ela com a dona Inocência em Belém (PA) em julho de 2001, e à Deize Melo por disponibilizar a entrevista transcrita. 
Duas guaritas de segurança funcionavam 24 horas por dia com telefone para controlar a entrada e saída de pessoas e automóveis, que eram revistados ao entrarem nas propriedades da Companhia. A CFIB exigia, com rigor, uma boa conduta de seus funcionários. Bebida alcoólica era proibida e qualquer deslize era objeto de demissão, segundo "a lei severa dos americanos".

A diversão era permitida, mas a ressaca ou qualquer tipo de situação que impedisse o ritmo do trabalho eram punidos com injeção, purgante, extração de dente ou outro procedimento adequado à situação de doença alegada, caso desconfiassem da história contada. Este controle era feito por um fiscal que passava nas casas verificando a presença de trabalhadores nelas, durante o horário de trabalho. Tudo para garantir o perfeito funcionamento do sistema fordista de produção, conforme o Senhor Erasmo.

Segundo ele, a disciplina imposta aos "desordeiros" era realizada pelo serviço de policiamento interno, denominados de "mata-cachorros", "porque naquela época era a lei da borracha, a lei da porrada mesmo". A punição não distinguia idade, era aplicada desde os velhos até aos menores de idade. Matasse, roubasse ou fizesse arruaça, o "desordeiro" ia para a cadeia.

A disciplina também se estendia sobre a vida dos filhos dos empregados da Companhia durante o processo de socialização na creche, como pudemos observar pela experiência de um filho de ex-seringueiros, que narrou situações de seus aprendizados e como este plano de referência foi usado na criação de seus próprios filhos ${ }^{47}$.

Os relatos também indicam que existiram formas de resistência no lugar, mas não foram suficientes para enfrentar a disciplinarização e a coerção do sistema fordista. Em Fordlândia teve o "Quebra-Panela", ato de insurreição, contra as precárias condições de trabalho e de alimentação ${ }^{48}$. Em Belterra, as tentativas de levar para a cidade cachaça escondida em bambu, côco ou melancia não resistiram às revistas nas guaritas de controle e nem à "descarga" (demissão) feita pela companhia contra os trabalhadores apanhados praticando algum "delito" considerado grave, conforme proibiam as regras de conduta da empresa.

O salário pago por mês era definido por produção no momento do acerto de contas, mas o resultado do trabalho era cobrado quinzenalmente. O não cumprimento dos acordos estabelecidos poderia levar à demissão do empregado sem qualquer indenização por parte da

47 Chardival Moura Pantoja, 71 anos, aposentado, filho de pais seringueiros, funcionários da CFIB, nasceu e se criou em Belterra. Entrevista realizada em março de 2011.

48 Este fato aconteceu em Fordlândia, no dia 22 de dezembro de 1930, e teve como elemento motivador a dificuldade da CFIB de abastecer com alimentos seus trabalhadores, o que implicou a introdução de produtos alheios aos hábitos alimentares da região, como o espinafre, por exemplo. COSTA, Francisco. O grande capital..., Op. Cit. 
empresa. Após a conclusão mensal do trabalho, seu desempenho era avaliado pelo capataz, gerente e chefe do escritório que podiam validar ou não a sua permanência na Companhia ${ }^{49}$.

Temos, então, o controle sistemático da vida profissional e privada da vida do trabalhador legitimado por contratos formais assinados no momento da contratação, e da submissão às condições impostas pela CFIB. Mesmo assim, a experiência fordista na Amazônia é considerada na memória coletiva um período de prosperidade, de grande movimentação, de chegada de novas pessoas, inclusive por via área dadas às dificuldades de deslocamento no interior da região e de "progresso" por seus antigos funcionários.

\section{O fim da experiência}

Os relatos indicam que a borracha de Belterra e Fordlândia não abasteceu o mercado norte-americano, mas fala-se que, de lá, eles levaram ouro, prata, madeira e outros minérios. $\mathrm{O}$ ouro de Belterra, por exemplo, foi escondido dentro de pedaços de Bambu. Pelo menos, esse fato ainda está presente no imaginário de alguns de seus moradores ${ }^{50}$.

A cidade-empresa fora criada com a promessa de ser a maior produtora de látex do mundo, que a CFIB utilizaria na produção de pneus e outros derivados para sua indústria automobilística nos Estados Unidos começou a mostrar fragilidades. O plano inicial da empresa era plantar três mil hectares por ano. Para tanto, seria necessário um contingente de 7.293 trabalhadores permanentes. Em 1931, só se havia plantado 400 hectares e arregimentado 3.100 trabalhadores. Em Belterra, esse número, em 1938, era de 1.200 e quatro anos depois (1942), a Companhia não desmatou, nem plantou nada e o número de pessoal trabalhando diminui para 2.184. Valores bem abaixo dos que constavam nos planos da CFIB. O projeto durou apenas 18 anos, desde a sua criação em Fordlândia, no ano de 1928, para, em Belterra, experimentar o seu fim, no ano de $1945^{51}$.

Contudo, ainda hoje [2013], se ouve o apito da sirene que marca o ritmo da vida na cidade, herança deixada pelos americanos. Perguntamos a um antigo morador da cidade por que a sirene ainda toca hoje. Ele nos respondeu:

49 AMORIM, Antônia Terezinha dos Santos, A dominação norte-americana no Tapajós, Tiagão, Santarém, 1995.

50 Antônio Delgado, 78 anos, ex-seringueiro..., Op. Cit.

51 Edsel Ford, o filho único do magnata americano, morreu em 1943. Coube a seu filho, Henry Ford II, assumir os negócios da família que, diante da situação de crise econômica da época, decidiu fechar várias frentes de trabalho da Companhia. Dentre elas, Fordlândia e Belterra que, no dia 05 de novembro de 1945 , foram repassadas ao governo brasileiro pelo valor US\$244.200, dinheiro que foi usado para saldar obrigações trabalhistas na Amazônia. A empresa tinha investido US\$ 20 milhões e seu patrimônio era avaliado em US\$ 8 milhões. Os prejuízos com o investimento foram de US\$ 9.276.655,04, conforme os valores de 1945. COSTA, Francisco, O grande capital..., Op. Cit. GRANDIN, Greg, Forlândia..., Op. Cit.

\section{8}


Ela toca por uma questão de uma tradição, uma tradição da época em que foi colocada pelos americanos, e que ela volta a lembrar justamente o tempo, o começo dessa empresa que era justamente o Henri Ford. Porque eu acredito que se tirar esse apito ... e nunca mais apitar fica uma coisa assim ... um pouco esquisito e mais triste para aquelas pessoas.

O que aconteceu em Fordlândia e Belterra, do ponto de vista empírico, significou a materialização da "fala do desenvolvimento" e do projeto de modernização capitalista proposto por Vargas para o Brasil. Temos, assim, a experiência da cidade-empresa com a estratégia do capital, que sob a guarda da ação estatal vai se localizar em lugares propícios ao seu desenvolvimento, próximos às fontes de energia e matéria-prima, e de fácil recrutamento de mão de obra. É a "modernização pelo alto" que passa a configurar, mesmo que de forma pontual, o processo urbano-industrial do desenvolvimento brasileiro ${ }^{52}$.

\section{Considerações finais}

Conseguimos por meio das análises realizadas identificar que o que aconteceu em Belterra difere em muito de situações evidenciadas durante o "boom" da borracha na Amazônia, no fim do século XIX e início do século XX, já que para aquele período temos as relações baseadas no sistema de aviamento que criava obrigações quase servis entre o seringueiro e o seringalista.

Belterra aparece para o cenário urbano não pelo espraiamento da periferia, como no processo urbano-industrial vivido por várias cidades brasileiras, mas através da urbanização pela verticalidade. Ou seja, pela articulação de espaços descontínuos propiciada pela ação seletiva do capital com base no apoio estatal, cujas escalas vão desde o lugar onde se realizou o projeto, passando pela mediação governamental nas esferas estadual e federal, chegando até aos Estados Unidos, onde se localizavam as fábricas de Henry Ford.

Para este caso, argumentamos que a urbanização deve ser entendida mais como evento, "um acontecimento de significância" 53 que se prolongou por 18 anos, e se realizou num contexto histórico de estagnação econômica da região (1912-1940) e, por isso, representou uma tentativa de reerguê-la econômica e politicamente por meio da aliança entre o grande capital, o Estado e as oligarquias da Amazônia. Mas, de forma alguma, deve ser confundido com o marco definidor da urbanização da Amazônia -a "fronteira urbana"-, que representa o surgimento das cidades que serviram de suporte para a implantação dos grandes projetos na região na década de $1970^{54}$. Embora com ela guarde alguma relação, visto ser a cidade

52 VIANNA, Luiz Werneck. Liberalismo..., Op. Cit.

53 SAHLINS, Marshall, Ilhas de história, Zahar, Rio de Janeiro, 1985, p. 191.

54 BECKER, Berta; MIRANDA, Mariana, O papel das cidades na ocupação da Amazônia, Convênio IPEA/CEPAL, Brasília, 1987. 
o lócus da (re)socialização da população migrante, da instauração do mercado de trabalho em bases assalariadas e do modo de vida urbano.

São as verticalidades, onde os lugares cumprem papéis definidos e específicos no circuito global da economia, que guardam especificidadem se comparada com a urbanização por expansão para as periferias ou por lugares contíguos característicos do processo de horizontalização da urbanização brasileira ${ }^{55}$.

A partir de 1946, Belterra já está sob o comando do governo brasileiro. Isso se prolonga até o início da década de 1990, quando surge o processo de emancipação da cidade. Mas isto, não faz parte das nossas preocupações nesse momento.

Recibido: 20/06/2013

Aceptado: 29/07/2013

55 SANTOS, Milton. Técnica, espaço, tempo, Op. Cit. TELLES, Vera, "Trajetórias urbanas: fios de uma descrição da cidade", In TELLES, Vera; CABANES, Robert (organizadores). Nas tramas da cidade: trajetórias urbanas e seus territórios, Humanitas, São Paulo, 2006. 